\title{
De la «Patria Grande» a la «Madre Patria»: Manuel Ugarte y el hispanoamericanismo español (1900-1930)
}

por

\author{
Manuel Andrés García \\ Universidad de Huelva
}

\begin{abstract}
El objetivo de este artículo es la revisión de una figura capital en el antiimperialismo latinoamericano, Manuel Baldomero Ugarte, a través de sus colaboraciones con el hispanoamericanismo de comienzos del XX. Partiendo de un análisis sobre la marginación sufrida por el intelectual y su obra durante décadas, centraremos el trabajo en sus aportes a tres de las principales revistas hispanoamericanistas de la época -La Rábida, Unión Ibero-Americana y Cultura Hispanoamericana- a fin de observar los puntos de confluencia entre este movimiento y el erudito argentino.
\end{abstract}

Palabras Clave: Manuel Ugarte; antiimperialismo; hispanoamericanismo; izquierda latinoamericana; América Latina-nacionalismo continental.

En 1973 Norberto Galasso publicó, tras dos años de trabajo en el Archivo General de la Nación en Buenos Aires, una obra titulada Manuel Ugarte en la que recogía toda la documentación allí presente sobre dicho autor. Fue ésta la primera incursión del historiador argentino en una figura que, como bien recalcaría con posterioridad, acabó convirtiéndose en «alguien absolutamente desconocido para el argentino medianamente culto que deambula por los pasillos de las facultades ${ }^{1}$. No exageraba. Pedro Orgambide, en el que sería su artículo póstumo, llegó a describir a Ugarte como «el gran olvidado del pensamiento político argentino» ${ }^{2}$. Otros, como el historiador Jorge Abelardo Ramos, ya en 1962 señalaría cómo «se publican entre nosotros toda

1 Ugarte, 1978: XII.

2 Clarín, Buenos Aires, 26 de enero de 2003. 
suerte de obras (...) pero el nombre de Ugarte no figura jamás» ${ }^{3}$. Lo cierto es que quien fue definido por Gabriela Mistral como el «Juan Bautista del hispanoamericanismo» no fue la única víctima del olvido por parte de la cultura oficial argentina, pero sí una de las más flagrantes.

Amigo, entre otros, de Leopoldo Lugones, Alfonsina Storni, José Ingenieros, Alfredo Palacios y Ricardo Rojas, Ugarte mantuvo una estrecha relación con figuras de la talla de Jean Jaurés, José Enrique Rodó, Amado Nervo, Rufino Blanco Fombona o José Santos Chocano. Una mera revisión a su correspondencia ${ }^{4}$ nos revela a un Ugarte vinculado con lo más granado de la intelectualidad, la política, el arte y la literatura de su tiempo: José de Vasconcelos, Juan Ramón Jiménez, José Carlos Mariátegui, Víctor Raúl Haya de la Torre, Manuel Seoane, Francisco García Calderón, Vicente Blasco Ibáñez, Ramón Gómez de la Serna, Salvador Rueda, Max Nordau, Jean Finot, Pedro Henríquez Ureña, Alcides Arguedas, Albert Thomas, Julio Antonio Mella, Camille Mauclair, Carlos Pereyra, José Eustasio Rivera, Tristán Marof, Juan Marinello, César Falcón, Rómulo Betancourt... Todos ellos intercambiaron noticias, con desigual frecuencia, con el argentino. Henri Barbusse, director de la revista Monde de 1928 a 1935, llegaría a incluirlo en su comité editorial junto a otras celebridades como Albert Einstein, Máximo Gorki y Upton Sinclair. Miguel de Unamuno, Rubén Darío y Pío Baroja no sólo se contaron entre sus amistades sino que fueron los prologuistas de sus primeros libros. Vista la larga relación de nombres y su trascendencia, contrastado el lazo que mantuvieron con aquel a quien dirigían sus misivas, la pregunta a hacerse es cómo pudo ser éste condenado al olvido durante tantos años.

Galasso, en el prólogo de La nación latinoamericana, da algunas claves a no desechar pero partiendo de un aserto innegable: cómo los distintos miembros de la Generación del 900 fueron cobrando paulatino reconocimiento frente a la omisión que se cernió sobre Ugarte y su obra. Así, mientras los primeros «a pesar de las enormes presiones, los silencios y los acorralamientos» lograron «hacerse conocer en la Argentina y en América Latina», Ugar-

3 La cita proviene del prólogo a la primera edición argentina de El Destino de un Continente, de Ugarte, en 1962. La obra había visto la luz por primera vez en Madrid, en 1923, siendo publicada en inglés por la editorial neoyorquina A. A. Knopf en 1925. No es extraño que Ramos insistiese en dicho prólogo cómo la figura de Ugarte era respetada y homenajeada en otros países mientras «la Argentina paga con silencio».

${ }^{4}$ El Archivo General de la Nación argentino publicó en 1999, bajo el título El epistolario de Manuel Ugarte (1896-1951), un catálogo de toda su correspondencia junto a una selección de cartas. En total diez volúmenes que revelan la profusión de contactos mantenidos por Ugarte a lo largo de su vida y el interés que despertaría su obra entre la intelectualidad de su tiempo. 
te correría distinta suerte, de modo tal que «un silencio total ha rodeado su vida y su obra durante décadas convirtiéndolo en un verdadero «maldito» 5 .

Para Galasso los motivos estarían íntimamente relacionados con la articulación que el intelectual argentino haría de, probablemente, los dos problemas políticos centrales de su país -y, por extensión, de América Latina- a comienzos del XX: la cuestión social y la cuestión nacional. Dos cuestiones que, irresueltas tras las independencias incluso en su vertiente identitaria, cobrarían nuevas dimensiones con la llegada del nuevo siglo. Así, la figura de Ugarte fue sumida paulatinamente en un olvido interesado que no se enmendaría hasta su reivindicación por Ramos. Y, pese a la honestidad intelectual de éste, con las limitaciones impuestas por una cultura oficial refractaria a su recuerdo.

¿Fue ésta una actitud sólo observable en Argentina o extensible al resto de América? Pues en esto, aun contraviniendo parcialmente lo dicho por Ramos, habría que hablar de una posición más bien extendida. Y es que, si Ramos subrayaría cómo Ugarte era recordado en el continente por el mural de Guayasamín en el que aparecía junto a Bolívar, San Martín y Albizu, también olvidaría la desidia editorial en lo que a su obra ideológica se refiere. Entre 1930 y 1953 -año en el que Ramos hizo su primer trabajo sobre Ugarte- no encontramos ni una sola publicación sobre éste que no esté restringida al plano literario. Y ni aun en éste podemos decir que su obra fuese especialmente promocionada, siendo España su lugar de edición más habitual. Sorprendentemente, para encontrar algún análisis de sus escritos políticos en este periplo, hay que mirar a Estados Unidos, con dos tesis en torno al tema: The political and economic future of Latin America according to the writings of Manuel Ugarte, de Paul Elmer MacPherson, presentada en la Universidad del Sur de California en 1941; y Manuel Ugarte and hispanoamericanismo, de Robert Welter Daly. Esta última sería publicada por la Loyola University de Chicago en 1949.

Hubo que esperar a que Ramos y posteriormente Galasso abordasen la figura de Ugarte para que esta corriente de silencio fuese paliada, dando paso a compilaciones, monografías y artículos sobre su vida y obra. No entraremos en lo que concierne a la labor de Ugarte como poeta y literato, pero sí en aquellos escritos centrados en su actividad ideológica. Galasso fue y sigue siendo uno de los más insistentes en la recuperación de su figura, con ensayos y antologías dirigidas expresamente a combatir la omisión sufrida por el autor ${ }^{6}$. Tampoco puede obviarse cómo el devenir político latinoamericano ha

\footnotetext{
5 Ugarte, 1978: XII.

6 Su última obra al respecto, Manuel Ugarte y la unidad latinoamericana, fue publicada el pasado 2012. No obstante, antes de ésta Galasso también enfocaría al intelectual argen-
} 
traído consigo, junto a la renovación del discurso unitario continental, un creciente interés por sus reflexiones. Así, a obras centradas en el análisis de sus textos y alocuciones habría que sumarle todas aquellas que lo vinculan con la problemática continental, movimientos políticos coetáneos o acontecimientos contemporáneos muy concretos ${ }^{7}$. Sorprende, sin embargo, el muy relativo interés despertado por la relación de Ugarte con el hispanoamericanismo. Podemos encontrar estudios sobre sus vínculos con el latinoamericanismo, el antiimperialismo, el socialismo,... pero no tanto con un movimiento hispanoamericanista con el que mantendría excelentes relaciones y que le abrió las puertas de sus publicaciones sin cortapisas ${ }^{8}$.

Afrontar este tema con cierta profundidad obliga a pasar casi de puntillas por encima de las relaciones que Ugarte pudo mantener con otros movimientos e ideologías. Entre otros motivos porque hablar de la ubicación de Ugarte y su obra respecto a las corrientes ideológicas y de pensamiento vigentes en la América Latina de esos años excede, con creces, las posibilidades de un artículo, salvo que se opte por una simplificación que no viene al caso. Lo mismo ocurre si intentamos desgranar la posición del autor dentro de un movimiento, el antiimperialismo, con un ascendiente sobresaliente en el ámbito político, ideológico e intelectual de este periodo, pero con un caudal de ex-

tino en Manuel Ugarte: un argentino "maldito" así como en Manuel Ugarte y la lucha por la unidad latinoamericana.

7 Entre las primeras merece la pena la lectura que hace de la obra de Ugarte Claudio Maíz en su Imperialismo y cultura de la resistencia: los ensayos de Manuel Ugarte, sin desmerecer tampoco los artículos en los que Margarita Merbilhaá desentraña las claves sobre Ugarte y su inserción en el entorno político y doctrinal de su tiempo. Sobre los últimos, un habitual a la hora de estudiar el latinoamericanismo es la obra de Miguel Ángel Barrios El latinoamericanismo en el pensamiento político de Ugarte; o los trabajos que, desde distintas perspectivas, han puesto la mira en Ugarte y la cuestión identitaria latinoamericana, como "La defensa continental de América Latina en el pensamiento de Manuel Ugarte y Victor R. Haya de la Torre (1900-1945)", de Eduardo Hodge Dupré, o los apuntes que Javier Moyano hace sobre el intelectual argentino en la compilación de Granados y Marichal, Construcción de las identidades latinoamericanas: ensayos de historia intelectual, siglos XIX y XX.

8 Tampoco con el indigenismo, si bien la relación de Ugarte con este movimiento -plural y complejo como pocos- fue mucho más tibia que la que mantuvo con la antigua metrópoli. Eso no quita para que Mariátegui, probablemente el único marxista original en lengua española y autor de una obra cumbre para la izquierda y el indigenismo peruanos, Siete ensayos de interpretación de la realidad peruana, reconociese su admiración por Ugarte y le invitase a participar en la revista que dirigía, Amauta. Más tratada ha sido su relación con Haya de la Torre, aunque cabría distinguir que ha sido más en su faceta de líder del APRA y su visión del continente que de los planes que pudiera tener respecto al indígena y el futuro del continente. 
presiones tal que, en su variedad, obligaría a una extensión muy superior de la que disponemos ${ }^{9}$.

Por tanto, este trabajo sobre todo pretende introducir la relación que el intelectual argentino mantuvo con tres importantes asociaciones hispanoamericanistas: Unión Ibero-Americana, Cultura Hispanoamericana y la Real Sociedad Colombina Onubense. Y constatar cómo el discurso antiimperialista no sólo fue bien recibido dentro de dichas sociedades sino también cómo acabaría influyendo en la línea editorial de sus principales publicaciones.

\section{La ARgentina INTERSECULAR Y SU INFLUENCIA EN EL PENSAMIENTO UGARTIANO}

La personalidad del joven Ugarte se forjó en una época de transición en Argentina caracterizada, entre otros, por la llegada masiva de inmigrantes.

Tras la caída de Rosas, en 1852, la política migratoria argentina dio un giro inusitado inspirado en las ideas plasmadas por Juan Bautista Alberdi en su Bases y puntos de partida para la organización política de la República Argentina. En resumidas cuentas, la posición de Alberdi podría concretarse en la frase «Gobernar es poblar», entendiendo por poblar «educar, mejorar, civilizar, enriquecer y engrandecer espontánea y rápidamente, como ha sucedido en los Estados Unidos ${ }^{10}{ }^{10}$. Tal premisa formaba parte de un plan de transformación estructural de la economía argentina en pos del modelo agro-exportador. Es decir, se pretendía desarrollar el sector agropecuario hasta hacerlo suficientemente potente como para insertarse en el mercado mundial $\mathrm{y}$, a partir de ahí, convertirse en proveedor del mercado europeo de lana, cereales y otras materias primas. Existía territorio para llevar adelante el plan -la Pampa húmeda - y también voluntad por parte del Estado para hacer los cambios legislativos que fuesen necesarios para fomentar la inmigración y la llegada de capitales. Los resultados no se hicieron esperar, siendo a partir de 1856 que comenzó a hacerse patente, aun de forma moderada, la llegada de inmigrantes europeos y, de manera más pronunciada, a partir de 1880 .

9 Una obra que aborda el asunto resaltando a Ugarte como uno de los primeros antiimperialistas es Pensar el antiimperialismo. Ensayos de historia intelectual latinoamericana, 1900-1930, coordinada por Alexandra Pita y Carlos Marichal, donde se enfatiza, desde distintas perspectivas y autores, la diversidad de corrientes intelectuales que influirán en el discurso antiimperialista de la época, el papel jugado en su evolución por el expansionismo estadounidense o la influencia de hitos como la Gran Guerra, la Revolución Rusa o la Mexicana en el devenir ideológico del movimiento.

10 Alberdi, 1915: 14. 
Un factor circunstancial que jugó a favor del proyecto fue el excedente de mano de obra generado en Europa por la tecnificación del agro y la Segunda Revolución Industrial. Esto garantizó un flujo constante de inmigrantes que todavía se vería incrementado con las posteriores crisis económicas europeas, siendo la mayoría de estos españoles e italianos para decepción de Alberdi y otros coetáneos como Sarmiento, cuyas preferencias iban dirigidas hacia la emigración británica y germana.

Pese a que las políticas de poblamiento fueron dirigidas a promover la agricultura, la ganadería y las redes de transporte como paso previo a la industrialización, la especulación latifundista hizo que el acceso a la propiedad de la tierra estuviese muy restringido para los recién llegados. Esto tuvo una doble consecuencia: por una parte, los nuevos colonos se vieron obligados, por lo general, a trabajar en régimen de arrendamiento o bien como aparceros; por la otra, las dificultades para acceder a la propiedad de la tierra hizo que muchos inmigrantes optasen por quedarse en el litoral acentuando el proceso de urbanización. Un gran número de ellos acabarían empleándose en la construcción del ferrocarril, pero su concentración en las ciudades tendría una consecuencia añadida: la paulatina organización del movimiento obrero y la expansión de los idearios socialista y anarquista por quienes habían llegado desde Europa con una formación ideológica consolidada. Gentes que no tardarían en ser tachados por las clases dominantes como «mala inmigración» ni en sufrir la represión gubernamental conforme se hicieron patentes sus actividades ${ }^{11}$. Fue contra ellos que se adoptaron medidas legislativas como la Ley de Residencia de 1902, también conocida como Ley Cané, que autorizaba al gobierno a expulsar, sin juicio previo, a los inmigrantes cuya conducta comprometiese «la seguridad nacional o el orden público»; o la Ley de Defensa Social, de 1910, que coronaría la anterior imponiendo un mayor control en la admisión de extranjeros y prohibiendo toda asociación y reunión que tuviese por objeto «la propagación de las doctrinas anarquistas o la preparación e instigación a cometer hechos reprimidos por las leyes de la Nación».

La coyuntura política y económica argentina influyó decisivamente en la conformación del pensamiento de Ugarte. El contraste entre el nuevo tiempo abierto con la llegada de los inmigrantes y la Argentina de los estancieros - una sociedad con marcadas reminiscencias rurales y un régimen político restrictivo y excluyente- ilustraría muchas de las facetas de lo que fue su vida: un

11 Especialmente violenta fue la represión del anarquismo en este periodo. Un libro aconsejable para acercarse a los comienzos del movimiento ácrata en Argentina es Anarquismo argentino (1876-1902), de Gonzalo Zaragoza Rovira. Otro a no desdeñar sería el clásico El Anarquismo y el movimiento obrero en Argentina, de Iaacov Oved. 
continuo enfrentamiento contra aquellas oligarquías que consideraba parasitarias, entreguistas y corresponsables de los males del continente; una denuncia permanente contra el expansionismo estadounidense y sus aspiraciones imperialistas al sur de Río Grande; una incesante reivindicación de la justicia social y de un socialismo alejado del positivismo decimonónico y sus lecturas semicolonialistas; y, por último, la exhortación perenne en pro de la unidad latinoamericana, recalcando su carácter colectivo, su identidad común, por encima de todo localismo.

Es el enlace de estos cuatro puntos el que puede llevarnos a entender cómo Ugarte pudo elevarse por encima de todo «patrioterismo», del «vacío internacionalismo de los partidos de izquierda tradicional» o de una posible fidelidad de clase $^{12}$ para retomar de un pasado no tan lejano la antorcha de la Patria Grande, aunarla a las ideas socialistas que iban extendiéndose por el continente y afrontar «la reconstrucción de la nación latinoamericana y la liberación social de sus masas trabajadoras». Una empresa que, para Galasso, explicaría la singularidad de Ugarte pero, sobre todo, «su condena por parte de los grandes poderes» ${ }^{13}$. ¿Cómo si no explicar que ningún editor argentino manifestase interés alguno por publicar en vida del autor alguno de sus originales? No fue hasta 1961, diez años después de su muerte, que una editorial argentina se decidió a ello -concretamente Ediciones Coyoacán ${ }^{14}-\mathrm{y}$ fue con una obra póstuma: La Reconstrucción de Hispanoamérica ${ }^{15}$. Hasta entonces todos sus libros, fuesen literarios o doctrinarios, habían sido editados en Europa y rara vez reeditados en su país o en Latinoamérica. Un detalle que el propio Ugarte auguraría al subrayar cómo había «sacrificado (sus) conveniencias de escritor para favorecer los intereses colectivos mientras tantos otros sacrificaban los intereses colectivos para seguir medrando a favor de lo existente» ${ }^{16}$.

12 Ugarte pertenecía a una familia económicamente muy acomodada, al punto que fue la fortuna paterna la que sostuvo durante 40 años su actividad como escritor y publicista, ya fuese en su faceta literaria o en la política.

13 Ugarte, 1978: XII.

14 Fundada en Buenos Aires, en 1961, por un grupo de intelectuales argentinos de izquierda entre los que se encontraba Jorge Abelardo Ramos, dicha editorial apenas tuvo dos años de existencia. En ese bienio publicarían hasta 38 obras de autores argentinos y uruguayos escasamente conocidos -entre ellos Ugarte- así como otros más clásicos, ideológicamente hablando, como Marx, Engels, Lenin... El nombre de la editorial se inspiró en el barrio de la capital mexicana en el que vivió y fue asesinado León Trotsky.

15 Pese a lo dicho, hay que señalar cómo en 1953 Jorge Abelardo Ramos había escrito un trabajo titulado Manuel Ugarte y la revolución latinoamericana. Ramos, 2011: 322.

${ }^{16}$ La frase la enunció en una conferencia pronunciada en Buenos Aires el 2 de julio de 1913 bajo el título "La resistencia del Sur". Ugarte, 1922: 93. 
Jorge Abelardo Ramos equipararía en diversas ocasiones el menosprecio hacia Ugarte a una muerte en vida, empleando un concepto, «cipayismo» ${ }^{17}$, para describir la actitud de la cultura oficial argentina ante todo aquello que fuese discorde a la «lógica de la factoría euro-porteña». Fue precisamente ésta una actitud contra la que Ugarte peleó durante toda su vida, al igual que contra todo aquello que -independientemente de su procedencia- pudiera considerar opuesto a la clase obrera, a su visión del socialismo o a la causa hispanoamericana.

Tal coherencia supuso la estigmatización del autor en la «irresistible Argentina del Centenario». Una Argentina orgullosa y rica ya convertida en el emporio triguero del mundo y con un potencial tal que un diccionario español de 1919 la señalaría como «llamada a rivalizar en su día con los Estados Unidos de la América del Norte, tanto por la riqueza y extensión de su suelo como por la actividad de sus habitantes y el desarrollo e importancia de su industria y comercio» ${ }^{18}$. Pero también una Argentina poco dispuesta a facilitar la vida a alguien que, como Ugarte, no contaba con el respaldo «de un partido, de una capilla, de los grandes diarios, o del orden vigente» ${ }^{19}$.

Dicha animadversión se complementaría con la manifestada por el resto de oligarquías del continente hacia el autor. No podía ser de otro modo. Sus continuas denuncias respecto al entreguismo de estos grupos a los intereses foráneos; sus manifestaciones contra el «imperialismo yanqui» y sus injerencias en los asuntos latinoamericanos, así como su apoyo a los alzamientos populares contra las arbitrariedades de los primeros y la desmedida ambición del segundo fueron motivos más que suficientes como para que los señalados procurasen el repudio del escritor y su obra... cuando no su persecución. No obstante, la firmeza del intelectual también le granjearía la admiración de muchos a ambas orillas del Atlántico. En España, en aquellos círculos que hicieron del hispanoamericanismo bandera. En América, sobre todo, entre aquellos sectores preocupados por el expansionismo estadounidense, y dispuestos a secundar toda manifestación que expresase su oposición al mismo.

17 Entendiendo por tal la simpatía que puede sentirse por los intereses extranjeros o el servilismo ante los mismos.

18 En concreto el Diccionario ARGO, publicado en España ese año. Polak, 2005: 1-192.

19 La frase está extraída de un documento de Jorge Abelardo Ramos que, bajo el título "Manuel Ugarte", puede encontrarse en el fondo digital del Centro Documental Jorge Abelardo Ramos. Accesible online. 
Ugarte y EL EXPANSIONISMO ESTADOUNIDENSE: EL PORVENIR DE LA AMÉRICA LATINA

La derrota de España frente a Estados Unidos sumió al país en una crisis moral, social y política sin precedentes, al punto de que fueron varias las generaciones de intelectuales que acabarían participando en un complejo debate sobre el «ser de España», lo que podríamos denominar «las esencias de lo español» y el por qué de su decadencia.

En la América Hispana la derrota española fue recibida en determinados círculos como la confirmación de la imparable hegemonía estadounidense, realzando al vecino del norte como el ideal de desarrollo político y económico. Sin embargo, la respuesta autocrítica dada en la Península al desastre hizo que muchos intelectuales hiciesen una identificación con sus propios problemas ${ }^{20}$; lo que vendría a acentuar el miedo cada vez más patente, vista la deriva final de la Guerra de Cuba, respecto al peligro potencial que suponía Washington para la independencia de sus propios países.

Ya con anterioridad pensadores como José Martí habían advertido la amenaza política latente en la ambición de sus vecinos, pero fue tras la derrota de España que se sumarían a la crítica un gran número de eruditos y literatos. Un caso paradigmático sería el de Rubén Darío quien, habiendo hecho ostensibles sus simpatías hacia el independentismo cubano $-\mathrm{y}$, más en concreto, hacia Martí- ese mismo año de 1898 haría público su rechazo a la intromisión norteamericana en un artículo de periódico, "El triunfo de Calibán", que sería publicado en El Tiempo de Buenos Aires, el 20 de mayo, y El Cojo Ilustrado, de Caracas, el 1 de octubre:

Y yo que he sido partidario de Cuba libre, siquier fuese por acompañar en su sueño a tanto soñador y en su heroísmo a tanto mártir, soy amigo de España en el instante en que la miro agredida por un enemigo brutal, que lleva como enseña la violencia, la fuerza y la injusticia ${ }^{21}$.

Muchas fueron las personalidades que irían mostrando su rechazo al expansionismo estadounidense -entre otros, Vasconcelos- pero si hubiese que señalar un antes y un después en el movimiento sería la publicación, en 1900, del Ariel de José Enrique Rodó. Partiendo de los principios de la tradición grecolatina Rodó incidiría en la necesidad de desarrollar los valores espirituales y éticos como base para una regeneración del continente, no ciñendo ésta

20 Sepúlveda Muñoz, 2005: 77.

21 En el periódico caraqueño fue publicado bajo el título "Rubén Darío combatiente". Jáuregui, 1998: 441-449. 
meramente a la inmersión en la utilidad material propugnada por el modelo estadounidense. Esa imagen de los Estados Unidos como sociedad regida por el utilitarismo y un bienestar material tan superficial como falto de estética -unido a las proclamas de calado más político sobre la amenaza que representaban- haría escuela y marcaría el discurso antiimperialista latinoamericano durante décadas. Un discurso que no tardaría en adoptar Ugarte como propio.

Los primeros artículos de Ugarte en este sentido fueron «El peligro yanqui» y «La defensa latina», publicados respectivamente en El País de Buenos Aires el 19 de octubre y el 9 de noviembre de 1901. La complementariedad de ambos textos es evidente, ya que si en el primero el escritor denunciaría las ínfulas expansionistas estadounidenses ${ }^{22}$ y sus estrategias para enfrentar a los gobiernos latinoamericanos a fin de justificar sus intervenciones, en el segundo la solución que presentaría como única alternativa a la política exterior de Washington sería la unidad de esa América Latina cuyo control se había convertido en objetivo prioritario del Departamento de Estado norteamericano.

El prestigio de Ugarte fue aumentando a la par que su actividad política y literaria. Su incorporación al Partido Socialista de la Argentina (PSA) en 1904 le llevaría a viajar como delegado al Congreso de la II Internacional Socialista celebrado en Amsterdam, repitiendo esta experiencia tres años después en el Congreso de Stuttgart. Su labor periodística también creció considerablemente durante estos años, siendo frecuentes sus colaboraciones en L'Humanitè Nouvelle de París, La Época y Helios de Madrid, así como en El País y El Tiempo de Buenos Aires.

Fue tras la reunión de Stuttgart que el escritor publicó un artículo, «Socialismo y patria», en el que esbozaría las bases de sus futuras discrepancias con Juan Bautista Justo. Justo era el fundador del PSA y, a su vez, de $L a$ Vanguardia, periódico en el que salió publicado el texto y órgano oficial del socialismo argentino. Lo cierto es que, pese a la coincidencia bajo las mismas siglas, las diferencias entre ambos eran notables tanto en su interpretación del

22 Algo sencillo si nos atenemos a un texto citado por Ugarte y que había sido publicado poco antes en el New York Herald de París: «Una nación de ochenta millones de habitantes no puede admitir que su supremacía en América sea impunemente comprometida. Sus intereses económicos y políticos deben ser defendidos, pueden emprender la obra de pacificación con la confianza absoluta de que es el derecho innato de la raza anglosajona. Deben imponer la paz al territorio sobre el cual tienen una autoridad moral y proteger sus intereses económicos y políticos a la vez contra la anarquía y contra toda inmiscusión europea». Ugarte, 1978: 66. 
socialismo ${ }^{23}$ como en la acepción del patriotismo o, siendo más concretos, del alcance de lo que podríamos llamar la cuestión nacional. Frente a un PSA que se declararía «antinacionalista» y que, en palabras de Galasso, disimularía «con fuegos de artificio del lenguaje clásico (...) su oportunismo hacia la oligarquía y el imperialismo reiterado una y otra vez en la política práctica» ${ }^{24}$, Ugarte manifestaría su convencimiento en cuanto a la necesidad y coherencia de un socialismo y un patriotismo unidos y planteados desde una perspectiva americanista:

Yo también soy enemigo del patriotismo brutal y egoísta que arrastra a las multitudes a la frontera para sojuzgar a otros pueblos y extender dominaciones injustas a la sombra de una bandera ensangrentada (...) Pero hay otro patriotismo superior, más conforme con los ideales modernos y con la conciencia contemporánea. Y ese patriotismo es el que nos hace defender contra las intervenciones extranjeras, la autonomía de la ciudad, de la provincia, del Estado, la libre disposición de nosotros mismos, el derecho de vivir y gobernarnos como mejor nos parezca. $\mathrm{Y}$ en ese punto todos los socialistas tienen que estar de acuerdo para simpatizar con el Transvaal cuando se encabrita bajo la arremetida de Inglaterra, para aprobar a los árabes cuando se debaten por rechazar la invasión de Francia (...) Todos los socialistas tienen que estar de acuerdo, porque si alguno admitiera en el orden internacional el sacrificio del pequeño al grande, justificaría en el orden social la sumisión del proletariado al capitalista, la opresión de los poderosos sobre los que no pueden defenderse. Por eso es que cabe decir que el socialismo y la patria no son enemigos, si entendemos por patria el derecho que tienen todos los núcleos sociales a vivir a su manera y a disponer de su suerte; y por socialismo el anhelo de realizar entre los ciudadanos de cada país al equidad y la armonía que implantaremos después entre las naciones ${ }^{25}$.

Ideas como las expuestas fueron el anuncio del que sería el primer gran ensayo del autor: El porvenir de la América Latina ${ }^{26}$. Publicado a caballo

23 Galasso lo resume con acierto al contrastar la naturaleza y evolución del PSA de Justo: «Nutrido en su base por artesanos extranjeros y en su dirección por pequeños burgueses acomodados de mentalidad liberal, este Partido reducirá su influencia a la ciudad de Buenos Aires y actuará, a lo largo de casi toda su historia, como ala izquierda del conservadorismo oponiéndose frontalmente a los movimientos nacionales. Disfrazado de fraseología socialista, resulta una expresión conservadora de la política argentina a tal punto que decae y se escinde en varios grupos sin importancia precisamente en la época de desarrollo industrial con el cual se constituye la verdadera clase obrera en la Argentina». Ugarte, 1978: XXIII-XXIV.

24 Ibidem: XXIV.

${ }_{25}$ La Vanguardia, Buenos Aires, 2 de julio de 1908. Ibidem: 197-198.

26 El libro sería reeditado posteriormente, en 1920, como El porvenir de la América Española. Según especificó el autor en el prólogo de esa reedición el motivo fue por considerar el título anterior un tanto vago y expresar mejor el nuevo su pensamiento. Margarita Merbilhaá, en un artículo en el que analiza la obra desde distintas perspectivas, habla de una 
entre 1910 y 1911, el libro se convirtió rápidamente en un referente para la intelectualidad coetánea. Dividido en tres partes, en él Ugarte insistiría en el peligro inherente al expansionismo estadounidense y la necesidad de una mayor unidad entre los países latinoamericanos para hacer frente común ante cualquier amenaza externa.

La diversificación en tres bloques - «La raza», «La integridad territorial y moral» $\mathrm{y}$ «La organización interior»- vino estructurada conforme a una visión pasado-presente-futuro que el escritor centraría respectivamente en la cuestión étnica, la coyuntura política y el proyecto de transformación multilateral a afrontar por el continente.

El por qué Ugarte abordó el tema racial en su ensayo hay que encuadrarlo dentro del debate heredado del XIX en torno al darwinismo social y la jerarquía de las razas. Fue éste un discurso que, a la sombra del positivismo y su idea de progreso, calaría hondamente en el ámbito político e intelectual, signando como certezas supuestamente científicas una larga serie de prejuicios que cuestionarían el aporte de toda etnia ajena a la blanca en cualquier proyecto de futuro. El número de intelectuales suscritos a tales tesis fue eleva$\mathrm{do}^{27}$, no faltando también aquellos que desecharon dichas teorías por infundadas y discriminatorias como Martí, Vasconcelos y otros de la talla de Manuel González Prada o Eugenio María de Hostos.

En el caso de Ugarte su tendencia a beber de las premisas positivistas quedó patente en el intento de definir la identidad continental a partir del análisis racial de sus poblaciones; o en la tipificación que llevaría a cabo de sus pobladores conforme a los rasgos morales con que caracterizaría a las distintas etnias. Sin embargo, dicha tendencia no le llevaría a comulgar con el determinismo biológico de manera tan extrema como Bunge o Sarmiento. Por el contrario, su postura estaría mucho más cercana a los planteamientos de Martí en cuanto a no ceñir inapelablemente los análisis sobre el continente a tales axiomas, al punto que ese mismo año, en una conferencia pronunciada en Barcelona, recalcaría cómo «el desarrollo inverosímil (estadounidense) que contrasta con el desgano de buena parte de América no se explica, a mi juicio, ni por la mezcla indígena, ni por los atavismos de raza que se

motivación fuertemente circunstancial dada por la cuestión de la latinidad en los distintos debates entablados al respecto en Europa así como en los relativos a la identidad americana. Merbilhaá, 2011b: 191-221.

27 Entre otros los argentinos Domingo Faustino Sarmiento, Octavio Bunge y José Ingenieros; los mexicanos Justo Sierra, Francisco Bulnes y Francisco Pimentel; el boliviano Alcides Arguedas; los cubanos Eusebio Hernández y Domingo Ramos; el peruano Francisco García Calderón; los brasileños Euclides da Cunha y Francisco José Oliveira Viana;... Casaus, 2010: 13-44. 
complacen en invocar algunos, arrojando sobre los muertos la responsabilidad de los propios fracasos ${ }^{28}$. Con ello el escritor se alejaría del determinismo radical para enfilar hacia postulados más dúctiles que encontrarían su expresión en la renuncia a pautas típicas del darwinismo social como la estigmatización del mestizo y su descripción como lacra u obstáculo para el progreso ${ }^{29}$.

La tendencia antiimperialista y unitaria de Ugarte cobró más vuelo en las otras dos partes del libro. Las circunstancias ayudaron a ello. Tras la firma del Tratado de París de $1898^{30}$ el interés de los Estados Unidos por todo aquello que acontecía tras su frontera meridional había crecido considerablemente y, con ello, sus intromisiones. En Cuba, por ejemplo, la aquiescencia norteamericana para que la Isla pudiera constituirse en Estado y tener su propia constitución estuvo supeditada a la firma de la Enmienda Platt, que otorgaba al gobierno de Washington el derecho a intervenir en los asuntos internos cubanos siempre que considerase amenazados sus intereses. Dicha cláusula hipotecó la soberanía cubana hasta un punto que -aun tras la derogación de la enmienda en $1934^{31}$ - no hubo decisión o acontecimiento político de relevancia en la Isla que no contase previamente con el beneplácito de la embajada estadounidense. Lo mismo puede decirse en el plano económico con la firma del Tratado de Reciprocidad Comercial, en 1903, que facilitó el control del mercado interno insular por parte de los Estados Unidos ${ }^{32}$.

Cuba no fue un caso aislado. Recordemos que la primera década del siglo XX fue la de la presidencia de Theodore Roosevelt, quien se convertiría en el principal valedor de la conocida «Doctrina del Big Stick o Diplomacia

28 Pronunciada en el Ayuntamiento de Barcelona el 25 de mayo de 1910 bajo el título “Causas y consecuencias de la Revolución Americana". Ugarte, 1922: 11-26.

29 «Pero dentro de la mezcla viviente de la futura raza sudamericana, el mestizo será uno de los elementos más aprovechables si, rompiendo la ignorancia que lo encorva, le hacemos levantar la frente y lo elevamos a la igualdad». Ugarte, 1911: 14.

30 Firmado el 10 de diciembre, en él España oficializaría la pérdida de Cuba, Puerto Rico, Guam y las Filipinas siendo Estados Unidos el gran beneficiario. La ausencia de representantes de los territorios en juego traería no pocos problemas en el futuro inmediato, sobre todo en el caso de Filipinas donde el descontento acabó desembocando en un conflicto armado entre el ejército norteamericano y los independentistas filipinos.

31 Una derogación, en todo caso, engañosa. Ésta se enmarcó en la firma de un nuevo tratado para regular las relaciones entre ambos países y, si bien conllevó la derogación de la polémica enmienda, también revalidó la cesión de la base naval de Guantánamo, punto clave para los Estados Unidos en su política de control sobre las Antillas y Centroamérica.

${ }^{32}$ Las exigencias norteamericanas llegaron a un extremo que Cuba pareció actuar más como un protectorado que como un estado independiente. Una muestra: mientras el tratado sólo concedía a Cuba un 20\% de rebaja de derechos, la administración estadounidense exigiría para sus productos reducciones que oscilarían entre el 20 y el $40 \%$. 
del Garrote» ${ }^{33}$. Dicho concepto ilustraría la voluntad del mandatario por negociar con sus adversarios y buscar un pacto, pero siempre con la amenaza de una intervención armada en caso de desacuerdo. Teniendo en cuenta que Roosevelt también postularía los desórdenes internos de las repúblicas americanas como peligros potenciales para los intereses comerciales estadounidenses, identificados como tales los de las grandes compañías, cabe entender cómo este discurso legitimó -cara a la opinión pública y la clase política norteamericana- las distintas intervenciones militares realizadas en esos años en las Antillas y al sur de Río Grande. La más relevante de todas ellas fue el apoyo a la independencia panameña -y probablemente su instigación- tras la negativa del Congreso colombiano a secundar la propuesta de Roosevelt para hacerse cargo de la construcción de un canal a través del istmo ${ }^{34}$. Una negativa revocada una vez consumada la secesión, en 1904, con la concesión a los Estados Unidos, por parte del nuevo gobierno panameño, de los derechos de construcción y explotación del canal a cambio de diez millones de dólares y una renta anual de 250.000 .

Aunque Ugarte dedicó el inicio del segundo capítulo a reflexionar sobre las diferencias entre la América anglosajona y la hispana ${ }^{35}$-el tercero lo enfocaría hacia el proceso de modernización institucional a abordar en pro de la unidad continental- la articulación de la obra la realizó engarzando los acontecimientos más relevantes del devenir político latinoamericano de comienzos de siglo con lo que había sido la política exterior norteamericana durante ese mismo periodo:

¿Hemos olvidado la exploración sintomática que la cañonera norteamericana Wilmington hizo, en 1899, en el río Amazonas, la tentativa del sindicato que pugnó algunos años después por hacerse dueño del territorio en litigio entre Bolivia y el Perú, la aventura inverosímil de la célebre república del Acre y el movimiento separatista del Panamá, que tan milagrosamente coincide con la apertura del istmo? ¿Quién ha prestado apoyo a las últimas revoluciones en Venezuela? ¿Dónde fue robustecida y alentada la insurrección que dio por resultado - no la libertad- sino el cambio de soberanía en Cuba ${ }^{36}$.

33 Así llamada por una frase enunciada por Roosevelt en una conferencia celebrada el 2 de septiembre de 1902: «Speak softly and carry a big stick; you will go far».

34 Un proyecto iniciado en 1879 con capital francés, a cuyo frente se puso Ferdinand de Lesseps y que, tras doce años de calamidades, acabó en quiebra sumiendo a la Tercera República Francesa en una crisis financiera inusitada.

35 Un debate latente en esos momentos con la cuestión racial como trasfondo, de ahí la importancia del primer bloque.

36 Ugarte, 1911: 48. 
Las críticas de Ugarte se extenderían a uno de los instrumentos más mimados por la diplomacia estadounidense: el panamericanismo. Un discurso que el Departamento de Estado norteamericano, a instancias de su gobierno, llevaba sugiriendo a los distintos gabinetes latinoamericanos prácticamente desde 1889, año en que se organizó la I Conferencia Panamericana en Washington. Para cuando el libro fue publicado acababa de resolverse la creación de la Unión Panamericana en la IV, celebrada en Buenos Aires; un nuevo ejercicio de tutela por parte de los Estados Unidos tal y como habían sido las anteriores reuniones ${ }^{37}$. Así, Ugarte tuvo motivos más que suficientes para manifestar su escepticismo respecto a las intenciones de Washington y argumentos sobrados para contemplar sus ofertas de diálogo como el embozo ideal de sus anhelos expansionistas:

La proximidad, lejos de favorecer la paz, la dificulta, y el panamericanismo es el engaño más peligroso, el error más funesto y capital. En nombre de él elaboramos nuestra ruina y favorecemos los intereses de la nación que nos amenaza. ¿Cuáles han sido hasta ahora los beneficios? El hecho de agruparnos de tiempo en tiempo bajo la tutela de los yanquis no ha contribuido a resolver ninguno de los problemas que nos sitian. Antes bien, las manifestaciones reglamentadas desde Washington sólo han servido para subrayar nuestro papel de satélites.

\section{(...)}

El mejor modo de poner de manifiesto la independencia de que nos jactamos, es discutir al aire libre los asuntos que nos conciernen. Nada puede impedirnos tratar estos tópicos con independencia y repetir que lo único que amenaza comprometer la suerte de las repúblicas de la América latina es la intrusión de los Estados Unidos ${ }^{38}$.

El éxito de la obra llevó a Ugarte a hacer una gira por el continente que se alargaría hasta 1913. En su recorrido el escritor haría escala en Cuba, Santo Domingo, México, Guatemala, Honduras, El Salvador, Nicaragua, Costa Rica, Panamá, Venezuela, Colombia, Perú, Bolivia, Chile, Uruguay y Paraguay. La experiencia le hizo constatar el ascendiente que el discurso antiimperialista tenía entre las clases populares, pero también la supeditación de la clase política a los dictados de Washington. Las presiones de las embajadas estadounidenses a lo largo de la gira fueron constantes. En México el gobierno y el congreso, instigados por su vecino del norte, estudiaron la posibilidad de prohibir sus conferencias. Hubo empresarios, incluso, que se negaron a alquilar sus locales y teatros. En Guatemala se le comunicó que podía hablar de lite-

37 La II en México, en 1901. En la III, celebrada en Río de Janeiro en 1906, se contempló la reorganización de la Oficina Internacional de las Repúblicas Americanas.

38 Ugarte, 1911: 67-68. 
ratura pero no hacer discursos contra los Estados Unidos. En El Salvador el presidente Araujo prohibió su conferencia "América Latina ante el imperialismo", pero las movilizaciones de estudiantes, al igual que había ocurrido en México, lograron que finalmente pudiera hacer su alocución. En Nicaragua, en ese momento con sus aduanas en manos norteamericanas, le fue vetado el ingreso. La voz de Ugarte llegaría incluso a los Estados Unidos, donde criticó ásperamente el despotismo de su gobierno para con las repúblicas del sur.

El discurso unitario de Ugarte también calaría profundamente en la intelectualidad, haciéndose presente en otros movimientos como el iniciado en pro de la reforma universitaria en Córdoba, Argentina, en 1918, y que terminaría esparciéndose por el continente aunando a las reclamaciones estudiantiles la reivindicación política. Sorprendentemente fue en Argentina, su propio país, donde con más recelo se acogería su mensaje. Incluso sus correligionarios criticarían las posiciones del escritor, siendo explícito el tratamiento que haría La Vanguardia sobre su gira: «Ugarte viene empapado de barbarie, viene de atravesar zonas insalubres, regiones miserables, pueblos de escasa cultura, países de rudimentaria civilización (...) y quiere complicarnos en el atraso político y social de esas pobres repúblicas ${ }^{39}$. El comentario habría que encuadrarlo en la polémica que dio pie a la salida de Ugarte del PSA. Cierto es que sus relaciones con Juan Bautista Justo nunca fueron fluidas, pero el apoyo de éste a la independencia de Panamá ${ }^{40}$-calificada como «progresista y civilizadora»- o su convicción sobre el imperialismo como vía de progreso $^{41}$ llevó la disputa a un punto sin retorno.

Las dificultades de Ugarte en su país contrastarían con el entusiasmo que su obra despertó en España. Ya hemos mencionado el gran número de amistades con las que contaba el escritor en la península, al igual que la fama de la que disfrutaba en los ámbitos literario e intelectual. Sin embargo, el nuevo libro supuso para el autor un reconocimiento sin paliativos, otorgándole una notoriedad que trascendería sus circuitos habituales abriéndole puertas hasta entonces entornadas, como las de un hispanoamericanismo que vería reflejadas en sus palabras no pocas de sus inquietudes.

\footnotetext{
39 La Vanguardia, Buenos Aires, 31 de julio de 1913. Galasso, 2008: 170-171.

40 Apoyo que incluiría una reprobación sin matices de las posiciones de Ugarte: «No es exhibiendo el espantajo del imperialismo yanqui como se van a redimir de la tiranía interna y de la posible presión exterior los pueblos latinoamericanos (...) Mucho y muy bueno tenemos que aprender del gran pueblo norteamericano». La Vanguardia, Buenos Aires, 25 de julio de 1913. Citado en Galasso, 2008: 170.

41 «Tenemos motivos para creer que la intervención o conquista de las repúblicas de Centro América por los Estados Unidos puede ser de beneficios positivos para el adelanto de las mismas». En La Vanguardia, 28 de mayo de 1911. Citado en Galasso, 2002: 35.
} 
UGARTE Y SUS RELACIONES CON EL HISPANOAMERICANISMO ESPAÑOL

El movimiento hispanoamericanista se gestó a finales del XIX y vivió su gran apogeo en el primer tercio del XX. Tras unas décadas de alejamiento en las que, salvo acontecimientos puntuales, fueron cerrándose las heridas de la independencia, la normalización diplomática entre la antigua metrópoli y las repúblicas latinoamericanas dio paso a una intensificación de las relaciones con un marco de fondo sobre el que se insistiría tanto por convencimiento como por necesidad: la existencia de una identidad cultural colectiva o, siendo más precisos, su concreción en comunidad cultural ${ }^{42}$.

No vamos a entrar a discutir los propósitos de las distintas corrientes del hispanoamericanismo - un movimiento heterogéneo con notables divergencias en su seno- pero sí a subrayar una coincidencia entre los mismos: la anteposición de los valores culturales hispanos y su defensa a cualquier interés comercial o económico. Dicha preeminencia no vino tan provocada por una posible imposición sentimental de la idea comunitaria como por la propia incapacidad española para afrontar proyectos integradores de mayor calado en la economía, el comercio o la política. Con todo, las actividades del hispanoamericanismo fueron profusas en este periodo, siendo cuatro sus principales líneas de acción: contrarrestar la leyenda negra; resaltar la identidad comunitaria, utilizando para ello un término entonces aceptado y con posterioridad polémico como raza; destacar la importancia de la comunidad idiomática y, por último, hacer hincapié en la realidad de la amenaza estadounidense. Todo ello, como bien señala Isidro Sepúlveda, «conjuntado en una suerte de misión unionista, cuyo fin era asentar la identidad de una comunidad hispano-americana y alcanzar su plasmación política» ${ }^{43}$.

El papel de Estados Unidos en todo ello fue trascendental. Si a lo largo del XIX la relación entre los países latinoamericanos y España se había significado por el distanciamiento -y, en determinados momentos, por la desconfianza- en la década de los noventa se produjo un cambio notable de la situación, entre otros motivos por las celebraciones del IV Centenario del Descubrimiento $^{44}$-a las que asistieron representaciones de las distintas repúblicas hispanoamericanas-y, sobre todo, por el Desastre del 98.

42 Sepúlveda, 1994: 18.

43 Ibidem: 20.

44 Que también se convertiría en un frente diplomático entre Washington y Madrid, por ver quién potenciaba con más fuerza sus relaciones en la América Hispana. Un artículo muy interesante sobre todo ello es "El IV Centenario del Descubrimiento de América en la coyuntura finisecular", de Salvador Bernabéu. También merece la pena, del mismo autor, 1892, el IV Centenario del Descubrimiento de América en España: coyuntura y conmemoraciones. 
Ya hemos referido cómo la debacle militar precedió a una crisis social, política y moral que dejaría honda huella en la intelectualidad. También la identificación que muchos intelectuales latinoamericanos harían de la crisis y la autocrítica española con la problemática de sus repúblicas. Fue éste un sentimiento que removería debates ya vigentes en América y en la propia España, como el referente a la herencia colonial. Frente a quienes habían hecho verdad irrefutable de la «leyenda negra»-es decir, de una reducción de la Colonia a la destrucción de las civilizaciones autóctonas, la brutal explotación de los indígenas y la esquilmación de las riquezas naturales del continente- hubo quienes implementaron una «leyenda blanca» tan sesgada como la anterior. Evidentemente el mantenimiento de un relato histórico con los odios seculares como fundamento imposibilitaba el acercamiento entre ambos continentes; pero la aceptación del otro discurso, subrayando las bondades de la colonización y omitiendo, cuando no trastocando, los temas más espinosos, dejaría pendencias abiertas que, por su propia naturaleza, el tiempo descartaría como consenso. Más interesante fue la vía que optó por abordar el pasado desde el trabajo científico y el análisis desapasionado de la documentación; una alternativa que podía consolidar una base desde la que abordar los futuros estudios americanistas. No obstante, entre medias de este largo rosario de reencuentros y desencuentros, se hizo evidente un acercamiento entre España y la América Hispana que se traduciría en una mayor presencia de la intelectualidad y cultura latinoamericanas en los foros de la vieja metrópoli.

En el caso de Ugarte, como ya mencionamos, el éxito de El porvenir de la América Hispana le convertiría en un habitual en las publicaciones americanistas españolas. Fuese como autor o como referencia, su figura cobró una relevancia que se iría incrementando gradualmente. Unión Ibero-Americana, sin duda la principal publicación americanista de ese periodo, empezaría a hacerse eco de las conferencias pronunciadas por un Ugarte cada vez más incisivo en señalar a Estados Unidos como el gran problema hispanoamericano, así como en hacer de España y su legado uno de los puntos de confluencia entre las diferentes repúblicas ${ }^{45}$.

45 «Por encima de las fronteras convencionales que dividen el nuevo mundo en veintitantos países diferentes está la diferencia real de las circunstancias; de los que viven en el norte, de las colonias que se separaron de Inglaterra y las que están en el sur que se separaron de la España y del Portugal. En el norte, los europeos que mantuvieron su raza pura; en el sur los que se mezclaron con las razas aborígenes; en el norte, los que después de la independencia trajeron las inmigraciones de Inglaterra, de Holanda y de los países escandinavos y en el sur, los que las trajeron de España, Francia, Italia y el Portugal; en el norte los que hablan 
No le resultó difícil a Ugarte significar la ambición estadounidense como una amenaza latente. En realidad la mejor avalista de sus críticas sería la propia diplomacia norteamericana y su actitud arrogante para con sus vecinos. Incluso los manejos de un político ya avezado como Elihu Root acabarían revelando una prepotente condescendencia que, sin embargo, en absoluto ocultaba las intenciones expansionistas de su gobierno.

Mr. Root -y citó al más pacífico de los imperialistas- subrayó esta definición en su respuesta a los delegados de Puerto Rico, que caídos en una situación de parias, sin nombre, sin patria y sin bandera, fueron á solicitar humildemente la ciudadanía americana. Cito palabras textuales: «Entre los latino-americanos y nosotros, no existe ni podemos tener nada en común: por grandes que sean nuestros deseos, no bastan para llenar el abismo que nos separa».

\section{$(\ldots)$}

El mismo Mr. Root nos da la voz de alarma en otro importantísimo discurso pronunciado en Nueva York hace seis meses. Voy á citar también palabras textuales: «Es cuestión de tiempo»-dice este pacífico ciudadano- «Es cuestión de tiempo que México, Centro América y las islas que aún nos faltan en el Caribe queden bajo nuestra bandera $>^{46}$.

Root había ejercido como Secretario de Guerra bajo la presidencia de McKinley y Roosevelt (1899-1904), y también como Secretario de Estado con este último. Ambos puestos le proporcionaron una gran relevancia en todo lo relacionado con el conflicto de 1898 y sus secuelas, de modo tal que cuando Ugarte lo señalaba como «el más pacífico de los imperialistas» no ironizaba: suyas fueron las iniciativas para devolver Cuba a los cubanos al igual que la de eliminar los aranceles a los productos de importación puertorriqueños. También fue idea suya promover en Filipinas un estatuto que garantizase un gobierno libre y la protección de las costumbres locales. No obstante, todas estas decisiones tendrían su lado oscuro: en el caso cubano, la Enmienda Platt; en el puertorriqueño, la normalización de una situación colonial de facto pese a la oposición interna; en el filipino, la defensa de la guerra sucia contra los patriotas del archipiélago ${ }^{47}$. No en vano Root sería considerado por muchos el arquitecto del panamericanismo y la cara amable de una política

inglés; en el sur, los que hablan castellano; allá los anglo-sajones; aquí, los latino-americanos». Unión Ibero-Americana, Año XXVII, nº 2, 30 de abril de 1913: 36. Accesible online.

46 Idem.

47 Un conflicto lamentablemente obviado por la historiografía española. Un estudio aconsejable como introducción es The Blood of Goverment: Race, Empire, the United States and the Philippines, de Paul A. Kramer. 
exterior que, cuando no lograba sus objetivos por cesión, lo hacía por la agresión.

Las invectivas de Ugarte contra el imperialismo estadounidense fueron creciendo a la par que el interés del hispanoamericanismo peninsular por sus palabras. Su "Carta a Wilson", por ejemplo, ocupó una de las portadas de Unión Ibero-Americana bajo el epígrafe «Una carta sensacional», haciéndose eco otras revistas como Cultura Iberoamericana que, si bien solía dedicar su atención más a temas culturales, no dejó pasar la oportunidad para mostrar su apoyo al intelectual argentino ${ }^{48}$. La carta en sí era una síntesis de lo vertido por Ugarte a lo largo de sus conferencias en América, desgranando en sus párrafos, aun de forma somera, el largo rosario de intervenciones protagonizadas por los Estados Unidos en el continente. La enmienda Platt; la escisión de Colombia tras la orquestada independencia panameña; las injerencias políticas y militares en Nicaragua; las continuas amenazas a un México convulso;... nada escapó a la pluma de un Ugarte que, en su indignación, no dejaría de reclamar respeto a quienes asumía, de hecho, como el peligro más acuciante para la América Hispana:

Deseamos que a Cuba se le quite el peso doloroso de la enmienda Plat; deseamos que se vuelva á Nicaragua la posibilidad de disponer de su suerte, dejando que el pueblo deponga, si lo juzga menester, a los que lo gobiernan apoyados en un ejército extranjero; deseamos que se resuelva la situación de Puerto Rico de acuerdo con el derecho y la humanidad; deseamos que se repare en lo posible la abominable injusticia cometida con Colombia; deseamos que a Panamá, que hoy sufre las consecuencias de su pasajero extravío, se le conceda la dignidad de nación; deseamos que cese la presión que se ejerce en el puesto de Guayaquil; deseamos que se respete el archipiélago de Galápagos; deseamos que se conceda la libertad al heroico pueblo filipino; deseamos que Méjico no vea siempre suspendida sobre su bandera la espada de Damocles de la intervención; deseamos que los desórdenes del Putumayo no sirvan de pretexto para habilidades diplomáticas, y deseamos que las compañías que extralimitan su acción no se sientan apoyadas en sus injustas exigencias; deseamos que la república de Santo Domingo no sea ahogada por

48 «Herida el alma sensible y generosa de Manuel Ugarte por la avaricia imperialista de los Estados Unidos - quizá fuera más propio decir que por su absorbente plutocracia-, que tantos atropellos y arbitrariedades va cometiendo desde hace no pocos años á la fecha en las naciones hispano-americanas, indignado su viril y justiciero espíritu contra ese fariseísmo que predomina en la América del Norte, en donde, á vuelta de todos los pretendidos humanitarismo de la raza anglosajona y de todos sus pujos de progreso, se llevan á cabo las mayores atrocidades de índole moral y material que darse puede (el lynchamiento á diario lo confirma), truena contra esa tutoría que más o menos descaradamente van ejerciendo los yanquis sobre los suramericanos, tutoría preparatoria de la explotación económico-financiera, que, por ahora, es lo que más les importa». Cultura Hispano-Americana, Año II, n 10, Abril 1913: 46. Accesible online. 
presiones injustificables; deseamos que los Estados Unidos se abstengan de intervenir en la política interior de nuestros países y que no continúen haciendo adquisiciones de puertos o bahías en el continente; deseamos que las medidas de sanidad no sirvan para disminuir la autonomía de las naciones del Pacífico; pedimos igualdad; pedimos respeto; pedimos, en fin, que la bandera estrellada no siga siendo símbolo de opresión en el Nuevo Mundo ${ }^{49}$.

El mensaje de unidad con que Ugarte salpicaría sus intervenciones aglutinó el discurso crítico contra los Estados Unidos independientemente del hecho al que se hiciese referencia. Incluso la actuación estadounidense en Filipinas sería utilizada por quienes censuraban el expansionismo norteamericano como si la agresión fuese a todos ellos. Cuánto más aquellas que se justificaron con motivos baladíes y dieron paso a intervenciones militares desproporcionadas, como el conocido incidente de Tampico que provocó el bombardeo y ocupación de Veracruz en 1914. Lo cierto es que ese compromiso mutuo, esa visión del «todos» como colectivo, fue ganando peso dentro de la intelectualidad latinoamericana. Y que el hispanoamericanismo y sus publicaciones fueron ámbitos en los que esto sería palpable indistintamente de la nacionalidad de los colaboradores. Buen ejemplo de ello sería el español Viriato Díaz Pérez ${ }^{50}$; una elección procedente en cuanto que también ilustra el creciente renombre de Ugarte en estos ambientes. Díaz, en su condición de colaborador de Unión Ibero-Americana, escribiría una carta al escritor que difícilmente puede superarse como ejemplo de la perspectiva comunitaria empleada por el hispanoamericanismo a la hora de valorar los planes, intrigas y confabulaciones de los Estados Unidos en el continente. La carta en cuestión versaba sobre la visita del ex presidente Roosevelt a Paraguay.

Es cierto que por doquier se ha presentado el profeta imperialista los gobiernos, por cortesía é internacionalismo, han procurado no deshacer el dulce encanto del «América para los americanos», pero los pueblos no han acompañado en su tarea de cortesía á los gobiernos (...) Bien está que los Gobiernos y los elementos conservadores, ensayen la nota de concordia; bien asimismo, acaso, que por acá algunos españoles, por hidalguía incurable, hasta contribuyesen metálicamente al homenaje al yanki; pero mejor ha estado que la juventud ibero-americana adoptase sin previo acuerdo espontáneamente, como unánime enseña común, el grito de ¡Viva Colombia! o ¡Viva México! Este lema extraño no ha representado, usted lo sabe, una justificación de la actual neurosis mexicana (mácula momentánea) sino la protesta contra el inmenso infortunio internacional que agobia a un pueblo her-

49 Unión Ibero-Americana, Año XXVII, no 3, 31 de mayo de 1913: 2. Accesible online.

50 Español de nacimiento y paraguayo de adopción, ya que se trasladaría a vivir al país americano en 1906 convirtiéndose en uno de los principales impulsores de la cultura paraguaya en la primera mitad del XX. 
mano. Y la juventud del Paraguay (quiero hacéroslo saber, pues que en este triunfo algún factor os corresponde) no ha permanecido ajena, á su manera, á estas explosiones de sinceridad ${ }^{51}$.

Hay que señalar que la misiva, pese a hablar de la «neurosis mexicana», fue publicada dos meses antes de los sucesos de Veracruz. Un hecho que provocó movilizaciones populares en toda la América Hispana e inspiró a Ugarte la creación de una corporación, la Asociación Latinoamericana, desde la que organizar protestas contra el intervencionismo estadounidense e impulsar la unidad continental. Esta sociedad todavía daría mayor prestancia a Ugarte quien, en su condición de «iniciador y presidente de la Asociación Latino-americana» pasaría también a ser presentado como «uno de los más insignes precursores de la política hispano-americana hoy triunfante» ${ }^{52}$.

La celebridad de Ugarte se puso de manifiesto en el viaje que haría por diversos puntos de la península en 1919. Prácticamente desde su llegada los homenajes serían constantes. La Real Academia Hispano-Americana de Madrid, el Ateneo capitalino y la Real Academia Hispano-Americana de Cádiz no tardaron en ofrecerse como escenario de las conferencias del intelectual porteño. El Centro de Cultura Hispanoamericana le propuso como socio de honor y mérito ${ }^{53}$, haciéndole partícipe de distintas reuniones, una de ellas la realizada el 4 de abril en la que se abordó la celebración de un Congreso Hispanoamericano a organizar en Sevilla como «proemio de la Exposición que se celebrará en 1921 en la misma ciudad donde reside el Archivo de Indias» ${ }^{54}$. Era éste un viejo sueño del Centro: la organización de un Congreso Cultural Hispanoamericano como continuación del Congreso Económico y Social de Madrid de 1900 y del de Geografía de Sevilla de 1914. Sin embargo, pese a que el plan lograría el aval oficial en repetidas ocasiones, no logró los apoyos económicos necesarios para llevarlo a cabo. En cuanto a la exposición, Sevilla tendría que aguardar hasta 1929 para ver plasmado el proyecto en la conocida Exposición Iberoamericana. Con todo, si por algo nos interesa la citada reunión es por el tema tratado en la misma:

51 Unión Ibero-Americana, Año XXVIII, no 2, 28 de febrero de 1914: 12. Accesible online.

52 La Rábida, Año VIII, no 89, 30 de noviembre de 1918: 11. La noticia hace mención a un viaje de Ugarte a España anunciada por el Heraldo de Madrid. Accesible online.

53 La propuesta se hizo en la reunión celebrada por la asociación el 23 de abril, constando así en las notas de la sesión. Cultura Hispanoamericana, Año VIII, nº 78, 15 de mayo de 1919: 2. Accesible online.

54 Cultura Hispanoamericana, Año VIII, $\mathrm{n}^{\circ}$ 77, 15 de abril de 1919: 1. Accesible online. 
discutir los criterios desde los que poner las bases de una legislación hispanoamericana ${ }^{55}$.

Ya comentamos cómo las asociaciones hispanoamericanistas tuvieron entre sus propósitos proyectos unitarios de ámbito diverso, al igual que subrayamos cómo la incapacidad española para afrontar los de mayor calado político, económico o comercial haría prevalecer la cuestión cultural por encima de cualquier otra. No obstante las propuestas para sacar adelante este tipo de planes justificaron iniciativas como la del Centro de Cultura Hispanoamericana. En el caso de Ugarte esto supondría su participación en una dinámica ciertamente relacionada con su visión unitaria, pero sin que dicha coincidencia implicase su adhesión a todos y cada uno de los postulados de estas asociaciones. Las causas de tal discordancia estarían íntimamente relacionadas con la dualidad ideológica existente dentro del hispanoamericanismo -pluralidad según el ámbito al que nos refiramos- de tal modo que bajo la misma vitola coexistieron asociaciones progresistas y conservadoras cuyas motivaciones, aun compartiendo un similar discurso de unidad, serían totalmente disímiles ${ }^{56}$. Así, el reconocimiento que Ugarte haría de la cultura española como parte sustancial del ser hispanoamericano no puede confundirse con un supuesto apoyo a los postulados panhispanistas hacia el que irían derivando los sectores más reaccionarios del movimiento, sino que habría que relacionarlo con los que, desde una perspectiva más progresista, buscaron el diálogo entre españoles y americanos a fin de «superar la crisis finisecular, la dependencia en política exterior de las grandes potencias y encontrar soluciones comunes a los problemas sociales $\rangle^{57}$.

Si la figura de Ugarte no sufrió menoscabo frente al conservadurismo hispanoamericanista fue, en buena parte, por su habilidad discursiva. Ésta le permitió combinar recursos que encajaban a la perfección dentro del imaginario más tradicional, pero sin renunciar a sus principios y, en particular, a la reivindicación de unidad de los países hispanoamericanos en régimen de igualdad. Basta un breve repaso al seguimiento periodístico de su itinerario español para encontrar sobradas pruebas de todo ello. En Huelva, por ejemplo, donde asistiría a las Fiestas Colombinas en calidad de «mantenedor», ofreció

55 Ibidem: 4.

56 La división vendría marcada fundamentalmente por la apreciación en torno al papel que España había tenido y debía tener en relación a América, generando una corriente conservadora denominada pan-hispanista, con un enfoque neocolonialista y paternalista de la relación, y otra progresista que se nutriría de movimientos intelectuales como el krausismo, el positivismo y el modernismo así como del regeneracionismo sociopolítico. Sepúlveda, 1994: 64.

57 Idem. 
a la Sociedad Colombina Onubense una alocución que haría las delicias de los sectores más «españolistas» del movimiento, resaltando la consideración que la «Madre España» tenía en todas y cada una de sus «hijas americanas»:

... más alta en su renunciamiento que en su esplendor, España recibe hoy el premio a que ha sido acreedora por su desinterés y conserva el afecto entrañable de los pueblos que surgieran de su seno, de las naciones que emanaron de su sangre, de la vida nueva a que dio lugar su cultura, oyendo el clamor de lejanas tierras con acentos de amargura y dolor, como si la voz de la Historia se elevase para decirle; ¡Madre! ¡Madre inolvidable! (...) ¡Madre! Los mares y las tierras, cuanto era tangible y material te ha sido arrebatado, pero las almas, $\mathrm{no}^{58}$.

Sin embargo, en el discurso que Ugarte pronunciaría apenas mes y medio después en el Ayuntamiento de Madrid para conmemorar el Día de la Raza, el argentino apuntaría su pragmatismo al reconocer a la vieja metrópoli como maternal origen pero, sobre todo, como raíz en torno a la que congregar una América Hispana separada por fronteras pero precisada de unión frente a los peligros del exterior:

Los cien millones de hombres que hablan en idioma español en el mundo, separados por la distancia, organizados políticamente en núcleos independientes, componen desde el punto de vista moral e ideológico un todo inseparable (...) Nos sentimos ciudadanos de un idioma, patriotas de una tradición, soldados de un recuerdo; y la bandera alrededor de la cual nos agrupamos, la fecha que celebramos hoy, (...) no es de guerra sino de paz, no es de controversia sino de concordia, no es un ímpetu para ir contra otras naciones, otros derechos $u$ otras esperanzas, sino una afirmación global de nuestra entidad superior, de nuestro ser completo, y esta afirmación hay que hacerla y repetirla para contribuir a la armonía del mundo, porque cada derecho respetado es una garantía de orden, seguros como estamos de que nadie ha de ver agresión u hostilidad en la estrecha unión de una familia que sólo aspira a mantener, al calor de la solidaridad fraterna, la integridad moral y material de sus fronteras, de su vida autónoma, de las reminiscencias comunes, de la propia cultura, de cuanto tienen la confraternidad y el afecto de franco, de emocionante y de inmortal ${ }^{59}$.

Tal pericia argumental fue la que permitió a Ugarte hacer complementarios dos discursos si no antagónicos sí divergentes en lo tocante a sus objetivos, suscitando un espacio de apoyo a sus tesis unitarias que se mantendría incluso cuando las premisas panhispanistas se impusieron dentro del hispa-

\footnotetext{
58 La Rábida, Año IX, no 98, 31 de agosto de 1919: 11. Accesible online.

59 Unión Ibero-Americana, Año XXXIII, nº VIII, diciembre de 1919: 26-27. Accesible online.
} 
noamericanismo en detrimento de posiciones más liberales ${ }^{60}$. Basta para constatar lo dicho con comprobar el seguimiento hecho desde las distintas revistas a la publicación de otra de sus grandes obras, El Destino de un Continente.

La Rábida se haría eco del nuevo libro con la divulgación de varios de sus fragmentos en una de sus portadas y páginas subsiguientes ${ }^{61}$, a lo que sumó dos meses después una crítica de su director, José Marchena Colombo, en la que elogiaría sin ambages las ideas en él expuestas:

... el libro de Ugarte es un libro de carne, de nervio y de sangre que debían leer todos los que amen la raza y sientan sin retóricas, en espíritu y verdad, el ideal Iberoamericano.

El Destino de un Continente», no es combate, pero sí una experiencia dolorosa que, de no escucharse se paga con las más terribles de las penas, con la de la pérdida de la libertad y con la de la patria mutilada ${ }^{62}$.

En el Centro de Cultura Hispanoamericana dedicaron tres sesiones consecutivas a su lectura y comentario, disponiendo poco después la publicación de uno de los capítulos en su revista -concretamente "Las Revoluciones Hispanoamericanas"- a fin de que sus lectores pudieran «formar juicio por sí mismos del verdadero mérito de dicha obra» ${ }^{63}$.

Unión Ibero-Americana, por su parte, editó diversos párrafos del primer capítulo del libro, "El lobo y los corderos", culminándolo con una reseña que casi podría describirse como una arenga a favor de la unidad hispanoamericana:

Desde luego, la tendencia del libro del ilustre propagandista nos satisface por completo en cuanto a la justicia, en reconocer la grandeza de la República norteamericana; de fustigar su imperialismo, y particularmente los procedimientos para imponerlo; de anatematizar a los políticos hispanoamericanos que se prestan a ser instrumento del pueblo que tiene esclavizadas a naciones hermanas; de alentar a las repúblicas iberoamericanas para que se dignifiquen cada vez más por decoro de la Raza, mediante el cultivo de las virtudes características y elementales propios de la misma; mediante el trabajo, el desenvolvimiento de sus cuantiosas riquezas

60 Proceso que se aceleraría en la década de los 20, sobre todo en el periodo primorriverista, y que si bien pudo cambiar con la llegada de la II República, mucho más pragmática e internacionalista en su política exterior, en lo que concernió a estas asociaciones supuso el triunfo de la vertiente más conservadora. Arenal, 1994: 1-312.

${ }^{61}$ La Rábida, Año XI, no 118, 31 de mayo de 1924: 1-3. Accesible online.

62 La Rábida, Año XI, no 120, 31 de julio de 1924: 2. Accesible online.

63 Cultura Hispanoamericana, Año XIII, no 137-138-139, Abril-Mayo-Junio de 1924: 18-26. Accesible online. 
naturales por su propio esfuerzo, para que siquiera por instinto de conservación se unan estrechamente contra el engreído enemigo de su independencia y explotador de la división de Sur-América y de las rivalidades intestinas dentro de cada uno de los estados que la constituyen ${ }^{64}$.

¿Era excesivo el entusiasmo mostrado por los redactores? No, simplemente reflejaba el que Ugarte despertó en un hispanoamericanismo satisfecho de encontrar un valedor de su talla y, por ende, latinoamericano. Que hubiese diferencias entre el pensamiento ugartiano y los postulados finalmente triunfantes dentro del movimiento en ningún momento llegó a ser óbice para que su figura fuese mentada con sumo respeto, ni para que obtuviese un reconocimiento desconocido por el autor en sus propias latitudes, al punto que bien podemos afirmar, parafraseando a Sepúlveda, que si Ugarte halló en España un altavoz adecuado para hacer valer su mensaje de unidad latinoamericana, la proclamada Madre Patria ${ }^{65}$ encontraría en él «uno de sus principales soñadores en América» ${ }^{66}$.

64 Unión Ibero-Americana, enero-febrero de 1924: 33-36 y 55-56. La portada no hace mención al año de publicación de la revista (XXXVIII) ni al número (1-2). Accesible online.

65 Un término al que tiende a dársele una interpretación conservadora por el acaparamiento que finalmente hizo del mismo esta ideología, ignorando cómo a finales del XIX y comienzos del XX su uso era común también entre los progresistas. Alguien tan poco sospechoso de conservador como el propio Ugarte lo utilizaría en algunos de sus principales textos antiimperialistas, como puede constatarse en El porvenir de la América Latina (Ugarte, 1911: 22, 33, 73 y 90), La nación latinoamericana (Ugarte, 1978: 20, 51 y 106), Mi campaña hispanoamericana (Ugarte, 1922: 11, 30, 40, 143 y 145) y El destino de un continente (Ugarte, 1962: 18, 25, 45, 168 y 172). El uso despertaba entonces tan poca polémica que Ugarte lo emplearía aun confrontando los motivos que separaban a España de la América Hispana: «Pocos hispanoamericanos quieren a España como yo. Pero en plena sinceridad debo declarar que, a mi juicio, falta entre la madre y las hijas el isocronismo en las vibraciones, que sería indispensable para realizar el porvenir (...) Ni aún en el plano de la diplomacia cabe imaginar una acción única de España y los países ultramarinos, los pueblos de América tienen su rotación, y España gira en la órbita de los intereses europeos. Pero respetando estos rumbos, impuestos por las circunstancias, cabría en cierto radio un enlace superior de finalidades. Sin invocar el pasado, sino la realidad del momento (...) Sin embargo, estas mismas direcciones experimentales requieren la base moral de una fraternidad efectiva y franca. Y ese es el sentimiento que acaso no existe aún con la debida intensidad entre nuestros pueblos» (Ugarte, 1962: 172). No está de más, en todo caso, revisar la reflexión que Aimer Granados hace sobre dicha expresión en Debates sobre España. El hispanoamericanismo en México a fines del siglo XIX.

66 Sepúlveda, 2005: 87. 


\section{Conclusiones}

Ugarte, su vida y obra reflejan la convulsión del periodo comprendido entre finales del XIX y comienzos del XX. Un tiempo de transición caracterizado, entre otros aspectos, por el imparable ascenso de los Estados Unidos en pro de la preponderancia geopolítica, la cada vez más patente presencia de los movimientos de clase en los distintos escenarios locales y un cambio de mentalidad que acabaría trastocando las estructuras e imaginarios tradicionales.

En el ámbito latinoamericano la creciente hegemonía estadounidense conllevó la desaparición de la antigua metrópoli española del panorama continental, así como el impulso por parte de Washington de una política de acercamiento a las repúblicas hispanoamericanas sin más objetivo que la imposición de sus intereses de facto o por la fuerza. Es en este marco en el que hay que encuadrar las posiciones políticas e intelectuales de Ugarte, al igual que el surgimiento de dos de los movimientos en torno a los cuales desarrolló sus actividades: el antiimperialismo y el hispanoamericanismo. Dichas corrientes, junto al socialismo, inspiraron las reflexiones del autor aunándose de tal modo que en muchos de sus escritos resulta imposible separarlas.

La coherencia de Ugarte con sus ideas fue la que le llevó a enfrentarse no sólo con los poderes tradicionales - de sobra ha quedado expuesta la animadversión que éstos le tenían en el continente- sino también con aquellos sectores que, siendo supuestamente afines en ideología, mostraron una interpretación distinta sobre lo que debían ser estos movimientos $\mathrm{y}$, sobre todo, sus objetivos. Fue aquí donde la vertiente antiimperialista cobraría mayor trascendencia. Porque, indudablemente, su propósito de unir la recreación de la patria latinoamericana y la liberación social de sus masas trabajadoras no podía eludir el enfrentamiento con unos Estados Unidos decididos a hacer de América Latina su coto particular, ni con unas elites locales acostumbradas a la dependencia financiera exterior, cuando no insertas en el sistema como delegadas de los poderes foráneos. Lo sorprendente sería la conformidad de sectores teóricamente afines a Ugarte en cuanto a ideología pero, sin embargo, condescendientes con una coyuntura internacional que no tardaría en ser confrontada por la intelectualidad latinoamericana. Fue precisamente el papel desarrollado por Ugarte en dicha confrontación, así como la crítica a sus correligionarios argentinos, la que provocaría su choque con Juan Bautista Justo y, de resultas de éste, su salida del PSA. No obstante, para lo que nos interesa, la principal consecuencia de todo ello fue la verificación del compromiso ugartiano con la América Hispana como colectivo, encarnado en la denuncia pública de toda acción que pudiera considerar agresiva contra cual- 
quiera de las «repúblicas hermanas» pero, sobre todo, en la regeneración que haría en sus textos del viejo sueño unitario de Bolívar y San Martín: la «Patria Grande».

Que Ugarte acabase siendo uno de los principales valedores del hispanoamericanismo español no deja de ser una paradoja que expresa en sí la complejidad de estos años. Expulsada del continente en 1898, España encontró en su derrota frente a los Estados Unidos la mejor coartada para recomponer definitivamente sus relaciones con una América Hispana a la que, pese a los desencuentros del pasado, había ido acercándose progresivamente desde los prolegómenos de 1892 y, ya de manera más decidida, tras las conmemoraciones del IV Centenario.

La empatía mostrada por los países latinoamericanos tuvo mucho que ver con su temor al expansionismo norteamericano. Cierto es que Cuba no fue la primera injerencia estadounidense en el continente, pero sí marcó un antes y un después en lo que a su intervencionismo se refiere. Puerto Rico, Dominicana, Colombia, Nicaragua, México,... todos ellos pasarían a sufrir la presión política, cuando no militar, del vecino del norte. Una presión colmada con la transmisión, por parte de Washington, de una imagen de superioridad con la que intentaría justificar la tutela que pretendía ejercer al sur de sus fronteras. Algunos sectores de las elites hispanoamericanas aceptarían esta imagen con naturalidad e incluso mostrarían su entusiasmo por el cambio; empero desde la intelectualidad se fraguaría un movimiento de respuesta que abarcaría del ámbito cultural al político. Fue dicho movimiento el que bucearía en el pasado reciente y remoto para reivindicar un legado hispánico que los aunara como colectivo frente a la avidez de la nueva potencia emergente. Y también fue éste en el que Ugarte brillaría con luz propia denunciando las agresiones y la prepotencia de unos Estados Unidos dispuestos a pasar por encima de quien fuese necesario para imponer sus designios.

Los escritos reivindicativos de Ugarte también le propiciaron una merecida fama dentro de los círculos hispanoamericanistas y, con ella, nuevos espacios de colaboración y difusión de su ideario. En realidad, podríamos decir que en Ugarte acabaron confluyendo dos doctrinas -antiimperialismo e hispanoamericanismo- unidas por la coyuntura y coincidentes en aspectos muy concretos, pero también con marcadas diferencias. Coincidencias y diferencias se hacen más evidentes según hagamos la comparación con los sectores más progresistas o conservadores de este movimiento. Sin embargo, en el caso de Ugarte sorprende la consideración que obtendría tanto de unos como de otros, al punto que sus artículos tuvieron cabida en distintos periódicos y revistas peninsulares independientemente de la ideología. Después de todo, el discurso unitario de Ugarte poco podía ofender a una España más volcada en recu- 
perar su imagen en el exterior que capacitada para empresas de mayor calado. Y, del mismo modo, el liderazgo moral que España quería asumir respecto a los países hispanoamericanos serviría a éstos $-\mathrm{y}$, más concretamente, a la intelectualidad antiimperialista- para congregar en torno a la herencia cultural recibida a aquellos sectores que replicaban las intenciones hegemónicas estadounidenses con su propia revalorización como colectivo. Un detalle que, aun de forma simple, explicará el olvido a que será sometido Ugarte por parte de aquellos a quienes se enfrentó en el continente y, sin embargo, la valoración que siempre obtuvo su obra en la antigua metrópoli.

\section{FUENTES}

Todas las revistas son consultables en el repositorio del Fondo Histórico Digital de La Rábida (Universidad Internacional de Andalucía).

- La Rábida: Revista Colombina Iberoamericana (Huelva: 1911-1933). URL: http:// dspace.unia.es/handle/10334/1055. (Fecha de consulta 12/06/2014).

- Unión Ibero-Americana. Órgano de la Sociedad del mismo nombre (Madrid: 19111926). URL: http://dspace.unia.es/handle/10334/2067. (Fecha de consulta 12/06/2014).

- Cultura Hispano-Americana (Madrid: 1912-1925). URL: http://dspace.unia.es/ handle/ 10334/740. (Fecha de consulta 12/06/2014).

BiBLIOGRAFÍA

Alberdi, Juan Bautista, Bases y puntos de partida para la organización política de la República Argentina, Buenos Aires, La Cultura Argentina, 1915.

Arenal, Celestino del, La política exterior de España hacia Iberoamérica, Madrid, Editorial Complutense, 1994.

Barrios, Miguel Ángel, El latinoamericanismo en el pensamiento político de Manuel Ugarte, Buenos Aires, Editorial Biblos, 2007.

Bernabéu Albert, Salvador, "El IV Centenario del Descubrimiento de América en la coyuntura finisecular", Revista de Indias, XLIV/44 (Madrid, 1984): 345-366.

Bernabéu Albert, Salvador, 1892, el IV Centenario del Descubrimiento de América en España: coyuntura y conmemoraciones, Madrid, CSIC, 1987.

Casaus Arzú, Marta Elena, "La representación del Otro en las élites intelectuales europeas y latinoamericanas: un siglo de pensamiento racialista 1830-1930", Ibe- 
roamericana. Nordic Journal of Latin American and Caribbean Studies, XL/1-2 (Stockholm, 2010): 13-44.

Galasso, Norberto, Manuel Ugarte, un argentino “maldito”, Buenos Aires, Ediciones Colihue, 1985.

Galasso, Norberto, Manuel Ugarte y la lucha por la unidad latinoamericana, Buenos Aires, Ediciones Corregidor, 2001.

Galasso, Norberto, ¿Cómo pensar la realidad nacional? Críticas al pensamiento colonizado, Buenos Aries, Ediciones Colihue, 2008.

Galasso, Norberto, Manuel Ugarte y la unidad latinoamericana, Buenos Aires, Ediciones Colihue, 2012.

Granados, Aimer y Marichal, Carlos (comp.), Construcción de las identidades latinoamericanas: ensayo de historia intelectual, siglos XIX y XX, México, Colegio de México, 2004.

Granados, Aimer, Debates sobre España. El hispanoamericanismo en México a fines del siglo XIX, México, UAM-Cuajimalpa, 2010.

Hodge Dupré, Eduardo, "La defensa continental de América Latina en el pensamiento de Manuel Ugarte y Victor R. Haya de la Torre (1900-1945)", Latinoamérica: revista de estudios latinoamericanos, 52/1 (México, 2011): 139-164.

Jáuregui, Carlos, “Calibán, icono del 98. A propósito de un artículo de Rubén Darío”, Revista Iberoamericana, LXIV/184-185 (Pittsburg, 1998): 441-449.

Kramer, Paul A., The Blood of Goverment: Race, Empire, the United States and the Philippines, Chapel Hill, University of North Caroline Press, 2006.

Maíz, Claudio, Imperialismo y cultura de la resistencia: los ensayos de Manuel Ugarte, Buenos Aires, Ediciones del Corredor Austral, 2003.

Marcilhacy, David, Raza Hispana. Hispanoamericanismo e imaginario nacional en la España de la Restauración, Madrid, Centro de Estudios Políticos y Constitucionales, 2010.

Merbilhaá, Margarita, "Representaciones finiseculares de los Estados Unidos en el socialismo argentino: los tempranos diagnósticos de Juan B. Justo y Manuel Ugarte", A Contracorriente, 9/1 (NCSU, 2011a): 237-269.

Merbilhaá, Margarita, "Claves racialistas y reformistas en la invención de un nacionalismo continental. El porvenir de la América latina (1911), de Manuel Ugarte”, Anuario de Estudios Americanos, 68/1 (Sevilla, 2011b): 191-221.

Orgambide, Pedro, "El largo viaje de Manuel Ugarte por América Latina”, Clarín.com (Buenos Aires, 26 enero 2003). (Fecha de consulta 12/06/2014).

Oved, Iaacov, El Anarquismo y el movimiento obrero en Argentina, México, Siglo XXI, 1978. 
Pita González, Alejandra y Marichal Salinas, Carlos, Pensar el antiimperialismo. Ensayos de historia intelectual latinoamericana, 1900-1930, México DF, El Colegio de México/Universidad de Colima, 2012.

Polak, Federico Gabriel, Un viejo diccionario español. La tontería del desarrollo argentino, Buenos Aires, Corregidor, 2005.

Ramos, Jorge Abelardo, "Manuel Ugarte"; 6 de febrero de 1985. Centro Documental Jorge Abelardo Ramos. URL: http://jorgeabelardoramos. com/ documento.php?page $=1 \& \mathrm{id}=14$ (Fecha de consulta 12/06/2014).

Ramos, Jorge Abelardo, Historia de la nación latinoamericana, Buenos Aires, Peña Lillo/Continente, 2011.

Sepúlveda Muñoz, Isidro, El sueño de la Madre Patria. Hispanoamericanismo y nacionalismo, Madrid, Marcial Pons Historia, 2005.

Sepúlveda Muñoz, Isidro, Comunidad Cultural e Hispano-Americanismo, 1885-1936, Madrid, UNED, 1994.

Swiderski, Gabriela (dir.), El epistolario de Manuel Ugarte, Buenos Aires, Archivo General de la Nación, 1999.

Ugarte, Manuel, El porvenir de la América Latina, Valencia, F. Sempere y Compañía, 1911.

Ugarte, Manuel, Mi campaña hispanoamericana, Barcelona, Editorial Cervantes, 1922.

Ugarte, Manuel, El Destino de un Continente, Jorge Abelardo Ramos (prol.), Buenos Aires, Ediciones de la Patria Grande, 1962.

Ugarte, Manuel, La nación latinoamericana, Norberto Galasso (comp. y prol.), Caracas, Biblioteca Ayacucho, 1978.

Zaragoza Rovira, Gonzalo, Anarquismo argentino (1876-1902), Madrid, Ediciones de la Torre, 1996.

Fecha de recepción: 25 de enero de 2013.

Fecha de aceptación: 4 de abril de 2013. 


\section{From "Great Homeland" to "Motherland": Manuel Ugarte and Spanish Hispano-Americanism (1900-1930)}

This paper aims to examine the role of a key figure in Latin-American anti-imperialism, Manuel Baldomero Ugarte, through his collaboration with early $20^{\text {th }}$ century Hispano-Americanism. Based on an analysis of the marginalization this intellectual suffered and his decade-spanning works, the study focuses on his contributions to three of the main pro-Hispano-American journals of the time -La Rábida, Unión Ibero-Americana and Cultura Hispanoamericana-so as to observe the of confluence between this movement and the erudite Argentinean.

KeY words: Manuel Ugarte; anti-imperialism; Hispano-Americanism; leftist Latin-America; Latin-America - continental nationalism. 